\title{
La comunidad sin fronteras. Lengua e identidad entre los ñäñho- urbanos de la ciudad de Querétaro
}

Community without borders. Language and identity among urban Ñäñho in the city of Queretaro, Mexico

Alejandro Vázquez Estrada

Doctor en Desigualdades e Intervención Social. Universidad Autónoma de Querétaro, Facultad de Filosofía. México

publicogeneral@yahoo.com.mx

Karola Rico García

Universidad Autónoma de Querétaro. México

jkarolarico@gmail.com

MINORÍAS ÉTNICAS, PROCESOS DE GLOBALIZACIÓN Y CONTEXTOS URBANOS

MONOGRÁFICO COORDINADO POR JOSÉ Ma VALCUENDE (Univ. Pablo de Olavide) e ISRAEL S. IDROVO LANDY (Univ. de Cuenca, Ecuador)

\section{RESUMEN}

Las poblaciones indígenas en las urbes latinoamericanas muestran un proceso de reconstitución y dinamismo de sus bases culturales e identidades. Sus estrategias a partir de las cuales construyen su comunidad, su identidad y su territorio tiene mucho que aportar a la antropología en cuanto a la reflexión vinculada a estos conceptos, tradicionalmente pensados desde ejemplos empíricos donde los pueblos indígenas se mantienen en sus territorios originarios. En el presente texto describimos y reflexionamos la manera en la cual los indígenas residentes en la ciudad de Querétaro, México reconstituyen los límites y fronteras de su comunidad en este caso a partir del uso de la lengua materna.

\section{ABSTRACT}

The indigenous populations in the Latin American cities are undergoing a process of reconstitution and dynamism of their cultural foundations and identities. The strategies by which they build their community, identity, and territory have much to contribute to Anthropology as a reflection linked to these concepts, usually conceived of based on empirical examples where indigenous people remain sedentary in their original territories. In this paper we describe and reflect the way in which indigenous people in the city reconstitute the boundaries and frontiers of their community from the use of language.

PALABRAS CLAVE

comunidad | indígenas | urbanos | lengua | territorio

KEYWORDS

community | indigenous | urban | language | territory

\section{Introducción}

La ciudad es un escenario complejo de experiencias sociales y culturales que se nutre de la diversidad y el dinamismo de los colectivos que la integran, los cuales al momento de apropiarse y significar el espacio dotan de vida y pertenencia a las calles y avenidas del mundo contemporáneo, dejando en cada una de sus esquinas su impronta identitaria imposible de no observar.

En América Latina, los grupos indígenas originarios de regiones distantes a las urbes establecen una serie de prácticas y representaciones colectivas, desde las cuales reproducen y reinventan un conjunto de valores y referencias que les permiten construir un sentido grupal en medio de un contexto que, por un lado, discrimina su presencia en términos económicos y sociales; y por el otro, es carente de una política pública para el reconocimiento y atención de sus particularidades culturales.

Es por ello que el reto de los indígenas en las ciudades tiene dos grandes dimensiones. Por una parte, se enfrentan ante la necesidad de asimilar la lógica cultural distinta que la ciudad impone; y por otra, tienden a utilizar sus bases culturales para construir las claves suficientes para salir adelante en sus distintas aspiraciones simbólicas y materiales. 
Entender los mecanismos a partir de los cuales los indígenas reutilizan los elementos culturales de su identidad, especialmente la lengua, es el objetivo del presente texto, el cual toma múltiples y variados ejemplos del trabajo etnográfico (1) realizado con los ñäñho (2) urbanos de la colonia Nueva Realidad en la ciudad de Querétaro.

\section{Los indígenas y la ciudad: reflexiones en torno a la comunidad y sus evanescentes fronteras.}

"No existe nada más valioso para los otomíes que sus hijos pequeños; los llenan de afecto y son el centro de atención de toda la familia extensa los primeros meses de vida" (Regina Martínez Casas 2002).

En la actualidad, los grupos indígenas que migran a las ciudades lo hacen para mejorar sus condiciones identitarias, monetarias y políticas. Lo que en otras décadas se simplificaba con la búsqueda de mejorar sus condiciones económicas, ahora representa búsquedas sociales y culturales de mayor estructura y profundidad.

Sin embargo, la migración indígena a contextos urbanos es un proceso que, al menos en América Latina, tiene más de 70 años de historia; misma que se cuenta a la par de la constitución de los grandes centros urbanos producto de la Segunda Guerra Mundial. Entender las ciudades latinoamericanas sin las manos de indígenas sería una visión incompleta, puesto que ellos han construido la urbe desde sus raíces. Son los que han edificado en la tierra los proyectos políticos de la modernidad y el desarrollo mediante la migración, ya sea de manera pendular, estacional o definitiva, los indígenas han dado heterogeneidad a las sociedades urbanas.

En México, por ejemplo, su presencia es inevitable en las ciudades más importantes del país. Sin embargo, en muchos casos, lejos de que la ciudad se convierta en destino definitivo de asentamiento, vemos que la comunidad originaria se expande y poco a poco va a la conquista de las urbes más allá de la fisicalidad de sus referentes culturales.

Es por ello que en este trabajo observamos a la migración como un "fenómeno multidimensional que genera cambios y crea repercusiones en los distintos órdenes de la vida cotidiana; porque los que se van, se llevan en los bolsillos un compendio social y simbólico que les da una identidad de abrigo; los que se quedan, lejos de mantenerse en un congelamiento cultural, tienen la difícil labor de generar las estrategias sociales para que la ausencia de vecinos y familiares no signifique una pérdida al interior de la trama comunitaria o familia" (Vázquez 2010: 136).

Y representa una posibilidad de auto-organización, resignificación y reconexión de la cultura originaria, en un contexto que implica adaptación y plasticidad de aquellos elementos propios para ser experimentados en situaciones distintas.

Cuando hablamos con jóvenes indígenas de cinco grupos etnolingüísticos (otomíes, nahuas, mazahuas, purépechas y triquis) presentes en la ciudad de Querétaro, ellos mencionan que en la ciudad aprenden a observar de distinta manera su origen y sus expresiones identitarias, revalorando los significados de su identidad, a partir de la comparación entre aquellas necesidades que tenían en sus comunidades originarias y sus nuevas carencias urbanícolas.

Como lo declara un joven indígena ñäñho de Santiago Mexquititlán: "la diferencia entre vivir en el campo y vivir en la ciudad tiene que ver con que la ciudad quiere dinero, en el campo no es tanto; allá uno siempre tiene que comer y aquí las tortillas son feas y caras". La ciudad quiere dinero es una frase que contiene dos ideas profundas para ser exploradas. La primera tiene que ver con concebir a la ciudad como una entidad viva, performativa, con agencia e intencionalidad, lo cual nos indica una interpretación que le da atribuciones de un sujeto vivo, no únicamente como un conjunto de estructuras materiales y sociales repartidas en espacios públicos y privados, sino una entidad viva con la cual disputan y consensan en su interacción cotidiana.

Por otro lado, se observa que el dinero es una unidad identitaria básica de la vida citadina, es el medio y la mediación (Barbero 1987) social de las relaciones culturales, el dinero es la forma de interacción simbólica intrínseca del medio urbano, con lo cual se consigue la accesibilidad a espacios, objetos, 
servicios y estados de ánimo; que cuando no se tiene, su ausencia posibilita la exclusión, la marginalidad y la asimetría socio-política. Actualmente el dinero se ha convertido para los jóvenes indígenas en un símbolo de estatus; sus padres y abuelos, con sus tradiciones y consejos, se quedaron en un mundo distinto al que llaman mundo moderno.

Los que se quedan en las comunidades de origen se quedan para cuidar la tierra, a los hijos y los abuelos. Los que se van, se van para buscar la vida y lo distinto, porque el pueblo es el lugar donde hay mucho trabajo por hacer y muy poco dinero por ganar. Esto último se hace patente en cada uno de los discursos de los interlocutores, al momento de narrar los motivos por los cuales migran, las frases recurrentes apuntan a que cada vez se necesita más el dinero, si quieres comer, necesitas dinero, si quieres pasear o tener novia, se necesita dinero, es por eso que nos venimos para acá, allá hay trabajo pero acá hay dinero.

Pero, además de la necesidad económica, la migración se sustenta en la existencia de una estructura social, un sistema de intercambio y reciprocidad en la familia, el barrio y la comunidad. Es por ello que podemos afirmar que la migración expande y contrae los escenarios donde los ritos de paso (Van Gennep 1986) tienen que ser desarrollados, desde aquellos vinculados con el nacimiento de los hijos hasta los asociados con la enfermedad y la muerte.

Podemos decir que cada grupo étnico tiene sus propias dinámicas de reconfiguración identitaria, basadas en un conjunto de necesidades culturales, a partir de las cuales han elaborado un complejo de aspiraciones colectivas cartografiadas en el horizonte de sus territorios originarios. Es por ello que, cuando hablamos de dichas dinámicas, nos referimos a patrones socio-experienciales, por los cuales, tanto individuos como colectivos, establecen su movilidad en un tiempo y en un espacio determinado.

La migración no solo transcurre en la dimensión espacial, puesto que se trata de una praxis que se desenvuelve en el tiempo, configura una historia y rehabilita una memoria, de modo que el periplo migratorio supone un aprendizaje y el manejo de ciertos conocimientos, basados en la transmisión inter/intra generacional. Asimismo, sucede en un plano temporal que se organiza a lo largo del año, generando calendarios cíclicos de temporadas laborales y sociales; de retornos y salidas que, en muchas ocasiones, articulan en acoplamiento perfecto las actividades agrícolas, políticas y rituales de las comunidades originarias con las temporadas vacacionales del turismo nacional e internacional de este mundo global, heterogéneo y asimétrico (Yúdice 2002).

En estas dinámicas de resignificación indígena urbana confluye todo un sistema de organización social que pone en juego conocimientos y experiencias, capaz de orientar los movimientos del colectivo en una comunidad que parece no tener fronteras. Esta conexión, que desde la antropología parece difícil de observar, los migrantes la hacen y la han instituido, desde varias generaciones atrás, como un estilo de vida, tal y como lo señalan Gupta y Ferguson al mencionar que "la premisa de la discontinuidad forma el punto de partida desde la cual se teoriza el contacto, el conflicto y la contradicción entre culturas y sociedades" (Gupta y Ferguson 1997: 34).

Entendemos la resignificación indígena urbana como redes activas de comunicación significativa que estructuran certezas identitarias, anclando en simultáneo conexiones espaciales en arenas culturales movedizas (Vázquez y Prieto 2013: 131). Estas redes están constituidas por un conjunto plástico y adaptativo de saberes, creencias y prácticas que se sociabilizan entre los distintos miembros de los colectivos. La trasmisión de ellos implica un sentido de comunitas (Turner 1999), ya que la transferencia significativa se establece con aquellos "nosotros" a los cuales, en términos de membresía y exclusividad, se les dota de un conjunto de conocimientos claves para el buen desempeño económico, social y cultural; tal como lo expresan Martínez Casas y De la Peña cuando proponen para su análisis de la resignificación de la etnicidad en la ciudad el concepto de las "comunidades morales" (Cohen 1989), manifestando que "los límites comunitarios, por ser negociables, trascienden el espacio físico ocupado por una colectividad. Lo que importa, finalmente, no es el lugar sino la pertenencia, y esta se define por un conjunto de elementos significativos que se manifiestan como fronteras simbólicas" (Martínez Casas y De la Peña 2004: 91).

Compartimos la idea de una construcción moral de la comunidad, pero antes que pensar que el lugar no importa para la comunidad imaginada, quizá sea bueno advertir que las comunidades morales que construyen los indígenas en las ciudades, frente a las relaciones asimétricas y frecuentemente hostiles, 
generan dinámicas de desconexión y reconexión permanente con los lugares que consideran como propios u originarios.

Por ejemplo, para los oriundos de Santiago Mexquititlán, lo santiaguero es hasta cierto punto un concepto de pertenencia desvinculado al territorio de origen en términos de la experiencia física del habitar, pero sigue presente en los territorios oníricos (mediante sueños), lingüísticos (mediante el uso de la lengua materna) y sociales (mediante ritos de paso); reconociendo que lo verdaderamente santiaguero está ligado "cada vez menos a un sitio limitado, que a una manera de ser imaginada o una locación moral" (Gupta y Ferguson 1997: 38), sino más bien es una articulación de espacios transterritoriales que genera un complejo dinámico que funda y desplaza territorios.

Es por ello que los barrios, vecindades y colonias de las ciudades de Monterrey, Guadalajara, Distrito Federal, Tijuana, León, Toluca, Cancún, San Luis Potosí o Querétaro, por donde han andado los santiagueros, aparecen como nuevos territorios anexos al pueblo mítico de origen, en los que la continuidad con la familia nuclear y el grupo parental se logra a partir de las mediaciones tecnológicas (las redes sociales se virtualizan y reestructuran mediante WhatsApp, Facebook y Skype); y la movilidad se convierte en un estilo de vida compartido y aceptado.

Pese a la distancia espacial y temporal subsiste entre los santiagueros el imaginario romántico del pueblo, con sus carencias invisibilizadas por la tranquilidad, la calma y el paisaje. El trabajo en la milpa, el cuidado de los animales y los potreros llenos de flores, desplazan en simultáneo las jornadas largas y extenuantes de trabajo, la enorme faena de ir por el agua al pozo, así como la violencia física, el alcoholismo y la enfermedad.

Esta visión mítica del pueblo se construye bajo una detallada selección de elementos culturales significativos de la comunidad imaginada. Dicha noción se lleva por todas partes incentivando el anhelo de la reproducción del pueblo nostálgico, melancólico y recordado. Eso que se le llama comunidad frecuentemente tiene rostro de familia, de barrio o de vecindad, nunca de un espacio territorial completo en su conjunto, jamás como una utopía concreta, siempre como una proyección deseable, móvil e inestable.

El anhelo identitario contiene símbolos dinámicos que necesitan de lugares nuevos para ser significantes, no importa que sea en una avenida o una calle, una escuela pública o un centro turístico, los nuevos contextos se vuelven elocuentes porque están vinculados a los deseos sociales anhelados.

En las ciudades, los indígenas se camuflan al mismo tiempo que muestran su identidad como un emblema frente a la sociedad en su conjunto, definen sus espacios públicos y privados al ritmo de sus interacciones simbólicas cotidianas; hablar en lengua se vuelve un recurso cultural que forma parte de la estrategia identitaria de conquista del espacio, en lengua se les dice a los colegas dónde se encuentran los mejores lugares para la venta, para dormir o trabajar. Así mismo se transmiten las amenazas y los apuros de las normativas sociales dominantes, se convierte en algo exótico y admirado por los turistas al tiempo que algo aborrecido y denigrado por la sociedad en general.

Los indígenas urbanos tienen reflexiones complejas al respecto y, sobre todo, cuando conciben a la ciudad y a sus pueblos originarios como lugares articulados de manera histórica e intrínseca, donde los caminos reales, las rutas de ventas y su nomenclatura inscrita en toponimias nos habla de una trayectoria donde la ciudad no es la que devora a los pueblos, sino que son los pueblos los que hacen a las ciudades.

Esta visión compleja y articulada de los territorios está presente en múltiples testimonios registrados con indígenas en las ciudades. Por ello, la comunidad parece construir territorios en todas partes. Los que no salen de los pueblos originarios se encuentran deleitados y anhelantes por las ideas del contexto lejano con el imaginario moderno, los que salen llevan a cuestas un conjunto de intenciones, valentías y recuerdos que les dan confianza y fuerzas para salir sin considerar necesario definir el cuándo y cómo regresar.

Las comunidades se construyen, por lo tanto, a partir de una dotación de símbolos que se adaptan mediante la interacción performativa de sus identidades, símbolos lo suficientemente rígidos como para dar certeza y estructura. Sin embargo, al mismo tiempo, estos son flexibles para decidir desde la 
plasticidad y la adaptación.

¿Dónde está la comunidad de un joven indígena migrante que vive en las ciudades de Monterrey, Nueva York, Querétaro, Ciudad de México, Cancún, Tijuana o Sevilla?, ¿cómo construye su pertenencia si en el lugar donde su familia tiene su residencia pasa menos de tres meses al año?, ¿cómo organiza sus relaciones económicas y sociales a lo largo del tiempo y el espacio para saber que tiene que regresar una vez al año al pueblo donde nació y viven sus papás?

Los urbanícolas estamos construyendo nuestra sociedad y grupo de pertenencia de formas virtuales, móviles e inestables. Actualmente, la fisicalidad, el mundo estructurado de forma objetiva y cara a cara no es indispensable para crear contactos. La información que circula en las redes sociales, y la tecnología de la mediación es hoy en día la forma para fundar y vivir en comunidades que van más allá del pueblo originario. Hoy en día hablamos de comunidades ambulantes donde la familia se construye mediante relaciones laborales, vecinales y situacionales. Se utiliza un código vagabundo que lleva consigo un conjunto de significaciones que interpretan y señalan el mundo, dividiéndolo en aquel mundo al cual se excluye o se pertenece, en aquel donde vale la pena la adaptación o es mejor idea la emancipación o la resistencia.

En los colectivos indígenas donde una de las bases culturales que conforman la identidad es la lengua, esta encuentra de manera histórica en espacios privados (familia y vecindad) el escenario donde se practica y se materializa. Sin embargo, hoy en día ya no son los únicos espacios; las lenguas indígenas encuentran en internet el contexto para la reinvención y el orgullo de la cultura, escribiendo palabras en sus lenguas y utilizándolo como forma de trasmisión simbólica e identitaria dentro de sus redes sociales, siendo los jóvenes los más doctos y ávidos en su propagación.

¿Qué sucede con la escritura y la verbalización de la lengua cuando escapa de los contextos sociales físicos de discriminación?, ¿qué implicaciones tiene internet en los procesos de revitalización, documentación y registro de las lenguas entre los jóvenes indígenas en las ciudades? Si las comunidades hoy se construyen mediante compartir, practicar y transmitir elementos simbólicos de una cultura específica, los indígenas urbanos están teniendo un papel muy importante en la resignificación identitaria de la lengua, escapando a los contextos tradicionales de asimetría y conquistando nuevos lugares de etnicidad.

Lo que a continuación presentamos es el estudio de caso de los ñäñho de la colonia Nueva Realidad, que, como su nombre lo indica, generan una forma distinta, contemporánea y estratégica para la reinvención de su cultura, donde la lengua tiene un papel importante para la definición compleja de la idea de comunidad.

\section{Los ñäñho en la Nueva Realidad (3)}

De acuerdo con el Censo 2010, en el país hay 6.695.228 de hablantes de lengua indígena (HLI) mayores de cinco años de edad: en el Estado de Querétaro hay 29.585 HLI y en el Municipio de Querétaro una población de $4.210 \mathrm{HLI}$, de los cuales 1.322 son hablantes de otomí. En el Estado de Querétaro se reportan 23.905 hablantes de otomí y en el país un total de 284.992 en 2010.

Vázquez y Prieto (2013) señalan que la población indígena del estado se integra en su mayor parte por los otomíes, quienes representan el $80,8 \%$ de los $\mathrm{HLI}$ a nivel estatal. Destacan dos núcleos compactos de población otomí territorializada, estas son Amealco y Tolimán, en donde se encuentra alrededor del $90 \%$ de los ñäñho del estado.

Desde hace más de 30 años existe un proceso de migración y conformación de residencias indígenas en las ciudades de México "haciendo de la ciudad su espacio preeminente de reproducción, y resignificando y reconectando los vínculos con sus pueblos de origen, con los que mantienen relaciones que suelen cambiar de sentido, aunque no necesariamente desaparecer, entre las nuevas generaciones" (Vázquez y Prieto 2014: 180).

Con relación al factor de la migración urbana, un diagnóstico (4) realizado en el 2008 por el Instituto Queretano de la Mujer (IQM) señala que en Querétaro existen varios lugares y asentamientos de 
población indígena otomí; como es el caso de las colonias de San Francisquito, Las Margaritas, Reforma Agraria, Lomas de Casa Blanca y la Nueva Realidad.

La Nueva Realidad es un asentamiento congregado $\underline{(5)}$ que se sitúa al norte de la ciudad de Querétaro, está conformado por indígenas otomíes provenientes en su mayoría de Santiago Mexquititlán y algunas familias originarias de San Ildefonso Tultepec, ambas poblaciones pertenecientes al Municipio de Amealco.

La colonia fue gestionada por un grupo de indígenas que emigraban temporalmente de su comunidad a la ciudad. En 1994 se asentaron 45 familias (17 otomíes y 28 mestizas), quienes formaban parte del Frente Independiente de Organización Social (FIOS), que posteriormente cambió su nombre a Frente Independiente de Organizaciones Zapatistas (FIOZ) debido a que sus ideales coincidían con los del Movimiento Zapatista. Después se integró la organización de otomíes Fuerza Hormiga Ñäñhu y la de mestizos La Nueva Realidad A.C.

El nombre de la colonia lo eligieron los colonos inspirados por el movimiento del EZLN en Chiapas. "También las calles habrían de hacer alusión a este movimiento: Libertad, Justicia, Democracia, Paz, Dignidad y Autonomía" (Prieto y Utrilla 2006: 305).

\section{Mapa de la colonia Nueva Realidad}

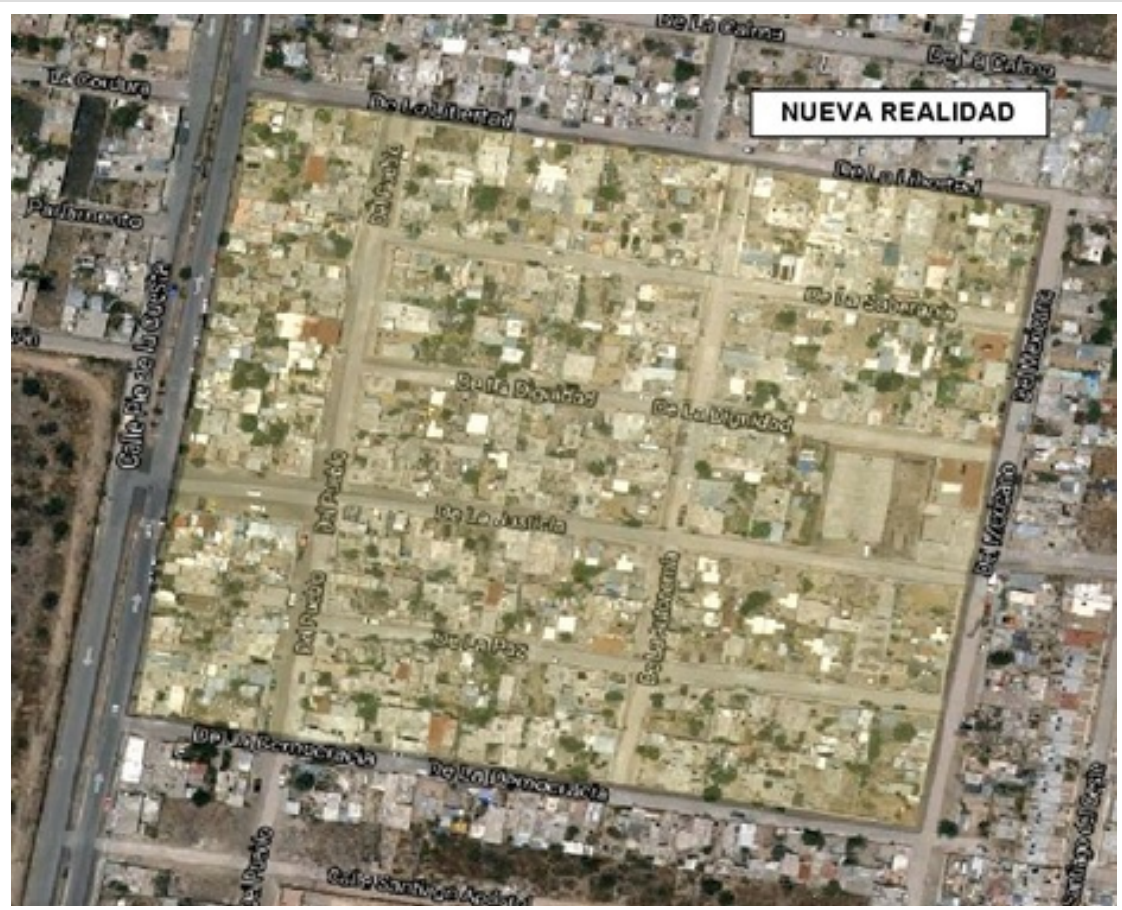

Fuente: Rico 2014, p. 41

En el estudio realizado por Murillo (2011) se menciona que los habitantes de la Nueva Realidad se unieron con organizaciones populares como Zapata Vive y otras colonias que iniciaban procesos de demanda de viviendas al gobierno. Tomaron terrenos irregulares, los negociaron con el gobierno y lotificaron después de una constante lucha, ya que en varias ocasiones se les exigió que abandonaran el asentamiento irregular. La perspectiva para la edificación de las casas fue la de entender la Nueva Realidad como una comunidad y no solamente como un espacio habitacional, de modo que hacían faenas para la construcción de las viviendas. "Fue un espacio de interacción universitaria, social y comunitaria. La Nueva Realidad era un punto de referencia de la lucha indígena en Querétaro, no había más lucha indígena más que en la Nueva Realidad" (Murillo 2011: 58).

Según Nieto (2010), por medio de presiones, manifestaciones, plantones y solicitudes a las autoridades por parte del grupo indígena Fuerza Hormiga Hñäñho, consiguieron la compra de lotes de 10 por 25 metros en $\$ 2.000$ (dos mil pesos) cada uno; mientras a los mestizos se les vendió en $\$ 5.000$ (cinco mil pesos). A las familias indígenas se les asignaron 60 lotes; así es como los otomíes de Amealco quedaron ubicados en las manzanas 342, 344 y 345; y de la 341 a la 343 solamente vive una familia indígena en 
cada manzana. En el diagnóstico del IQM se indica que en la colonia hay presencia de personas provenientes de 14 estados de la República, del D.F. y de 10 municipios del Estado de Querétaro.

La colonia cuenta con los servicios básicos de transporte, agua potable, luz y caminos sin pavimentado. Las calles son en su mayoría de terracería y la calle principal de empedrado. Hay presencia de zonas baldías. La Nueva Realidad está conformada por 10 calles y 17 manzanas. Existen pequeños comercios manejados por mestizos e indígenas que residen en la misma colonia o en colonias aledañas.

De acuerdo con Vázquez y Prieto (2013), las viviendas de los ñäñho están construidas con muros de ladrillo o vigas de madera, techo de loza o de láminas de asbesto; las fachadas por lo general están delimitadas con vigas de madera, ladrillos o alambrado. La mayor parte de las casas permanece en obra gris, sin aplanados, ni instalaciones completas, en calidad de vivienda progresiva. También se pueden apreciar todavía unas cuantas casas de cartón, con techo de lámina y piso de tierra. Asimismo, existen unas 10 viviendas prefabricadas entregadas a través de programas gubernamentales.

En Rico (2014) se muestran patrones culturales de la comunidad reproducidos en la ciudad, por ejemplo, "una caña de maíz creciendo en una pequeña jardinera sobre la acera, el cual fue sembrado por los dueños del predio argumentando que ellos mismos habían sembrado el maíz en esta porción de tierra con semillas que habían traído de Santiago Mexquitilán". Esto nos deja en manifiesto una inquietud relacionada con la comunidad de origen y la manera en la cual se trasladan los elementos culturales al lugar de residencia. La mayoría de las viviendas guarda similitud con las casas tradicionales en la comunidad de origen. Las casas cuentan con un patio al frente que tiene diversas funciones: es un espacio de reunión para la familia, el área de juego para los niños, donde preparan la mercancía que venden, guardan los carritos en los que salen a vender sus productos, y es el espacio utilizado para lavar y tender la ropa. Asimismo, se puede observar que en los patios prevalecen algunos elementos culturales vinculados con la alimentación de los ñäñho, como es el caso del fogón, el brasero y el comal para hacer las tortillas a mano, así como el cultivo de nopales para el consumo familiar. Estos espacios son lugares privilegiados donde la lengua y la cultura se vuelven performativas, el habla y la práctica se hacen evidentes de una generación a otra.

De acuerdo con el INEGI, en 2010 el número de viviendas por manzana en la Nueva Realidad ascendía a 233, sumando un total de 65 viviendas en las tres manzanas (342, 344 y 345), en donde se concentra la población otomí. Se reporta un total de 993 habitantes en la colonia Nueva Realidad, de los cuales entre 169 y 189 son hablantes de lengua indígena mayores de tres años de edad al interior de la colonia.

En la imagen se muestra la distribución de hablantes de lengua indígena (HLI) en la colonia Nueva Realidad, las manzanas en donde aparece -6 , se refiere a que en esa manzana viven menos de seis hablantes de lengua originaria, por lo que el INEGI no contabiliza a estas personas como HLI. A partir de los criterios del censo se puede observar el fenómeno de la invisibilización de la población indígena en la ciudad.

\section{Distribución de HLI en la colonia Nueva Realidad}

Población mayor de 3 años de edad 




Fuente: Rico 2014, p. 52

Sobre la cuestión lingüística, las cifras ofrecidas por INEGI $\underline{(6)}$ guardan relación con aquellas proporcionadas por el diagnóstico del IQM en el que se señala que en 2008, 128 de los 278 otomíes eran monolingües en español, 148 bilingües y solo dos monolingües en otomí.

\section{Lengua e identidad entre los ñäñho urbanos}

"Son indios que ejercen su cultura propia hasta donde la vida en la ciudad se los permite. No es raro que, frente a "los otros", oculten su identidad y nieguen su origen y su lengua (...). Pero esa identidad subsiste, enmascarada, clandestina y en virtud de ella se mantiene la pertenencia al grupo original, con todo lo que significa de lealtades y reciprocidades, derechos y obligaciones, vinculación y práctica de una cultura común y exclusiva" (Guillermo Bonfil Batalla 1987).

Para comprender la relación lengua e identidad entre los otomíes urbanos hace falta enfocar la mirada a la situación de la lengua originaria en el entorno inmediato de dichos hablantes o no hablantes. Rico (2014) presenta un diagnóstico sociolingüístico en la colonia Nueva Realidad donde se hace una revisión de los usos de la lengua originaria en la primera, segunda y tercera generación; la habilidad, la valoración y actitudes hacia la misma; aspectos relacionados con la propia identidad, la cultura y la percepción sobre la escolarización.

Con respecto al uso del hñäñho se encontró que la primera generación utiliza en mayor medida la lengua indígena, pues así lo han hecho desde pequeños ya que la mayoría de ellos nacieron y crecieron en Santiago Mexquititlán. Esta generación habla en la lengua originaria en casi todos los ámbitos en el pueblo y en el interior de la colonia. La segunda generación sigue haciendo uso de la lengua, la mayoría de los padres habla español y otomí, pero cuando llegaron a la ciudad sufrieron discriminación por hablar una lengua distinta, la misma que dejaron de hablar y enseñar a sus hijos, y se vieron obligados a aprender la lengua de dominio, el español. Esta generación hizo una pausa en la transmisión de la lengua originaria a las nuevas generaciones, consideraban que era importante que los hijos aprendieran la lengua del entorno, pues seguir hablando el otomí en la ciudad les representaría un atraso y podrían ser víctimas de discriminación. Esta idea se tenía presente también en el lugar de origen, la educación castellanizante en las escuelas forzaba a los hablantes de otomí a usar cada vez menos su lengua. Algunos padres de familia que habían aprendido el español durante las temporadas en las que migraban para trabajar en las ciudades comenzaron a enseñar a sus hijos el español. Esta es una de las causas por las cuales son pocos los hablantes de otomí de la tercera generación, pues se han desenvuelto en el 
ámbito urbano la mayor parte de su vida, no obstante, gran parte de ellos comprende cuestiones básicas en la lengua de sus padres.

La habilidad lingüística en otomí es muy variable en las distintas generaciones. La generación de los abuelos considera que el otomí es la lengua que habla y comprende mejor, mientras que esto no sucede en la segunda y tercera generación, pues han crecido fuera de la comunidad de origen. Cabe destacar que dentro de los factores que han favorecido a que se continúe con el uso del ñãñho es la interacción entre vecinos otomíes que hablan la lengua en la colonia y el contacto con la familia en la comunidad de origen, pues la mayoría de los interlocutores viaja con frecuencia a Santiago Mexquititlán, sobre todo para las fiestas del pueblo a pesar de que no todos tienen casa o tierras allá:

"En las fiestas en Santiago hablo en otomí, porque llega mucha familia, muchos conocidos, en la fiesta nos saludamos, hablamos otomí, vamos a pasear un rato, vamos a tomar un refresco porque a lo mejor nos podemos separar y no nos volvemos a ver y cada quien por su lado" (Alberta, 50 años).

Por otra parte, sobre las actitudes lingüísticas se mostró que éstas son positivas hacia el otomí. Además, la población bilingüe se siente orgullosa de hablar las dos lenguas. Asimismo, los interlocutores están interesados en conservar y difundir su lengua y su cultura, destacaron la importancia de enseñar el ñäñho en el hogar pues no quieren que se pierda, sienten orgullo por su lengua materna y quieren que las nuevas generaciones la aprendan y la hablen:

"Si dejara de hablar otomí no dejaría de ser otomí, porque tenemos una raíz, sabemos de dónde venimos, y no hay que hacer un lado nuestra raíz. Muchos ya se sienten orgullosos porque ya saben hablar el español y ya viven aquí (en la ciudad) y les da pena decir 'yo vengo de allá', pero yo me siento orgullosa de que tengo una raíz donde yo vengo" (Macaria, 39 años).

Por su parte, los jóvenes quieren aprenderla para ser parte de las conversaciones de sus padres, ya que, como se mencionó, estos hablan la mayor parte del tiempo en otomí. A Ismael, uno de los jóvenes ñäñho de la Nueva Realidad, le gusta cantar rap y compone canciones. Compartió un poco de sus letras e hizo énfasis en enseñar a los niños sobre la cultura otomí para que se sientan orgullosos de sus raíces:

"Yo me siento orgulloso de donde soy,

Soy más mexicano que el maíz,

No me olvido de donde vengo,

Yo sé dónde está plantada mi raíz,

Estoy bien plantado en mi raíz" (Ismael, 17 años).

Lo anterior coincide con las observaciones hechas por Martínez Casas (2007) con respecto a que una de las principales preocupaciones de los migrantes es evitar que los jóvenes pierdan la lengua indígena.

Si bien, lengua para los otomíes de la colonia Nueva Realidad representa una riqueza cultural que no debe perderse, consideran que la lengua no es el único factor que determina la identidad ñäñho. En el estudio sociolingüístico antes mencionado se muestra que los otomíes de la Nueva Realidad son conscientes del desplazamiento de la lengua originaria. Sin embargo, consideran que si un miembro de la comunidad deja de hablar la lengua originaria, este no deja de identificarse como ñäñho. Ser otomí se lleva en la sangre, en la memoria de los antepasados, en el reconocimiento, el sentimiento de orgullo por las raíces, en la sociabilización de estos elementos simbólicos y en la transmisión intra/inter generacional de estos elementos.

En Bartolomé (1997) y Vázquez y Prieto (2014) se señala que existen grupos indígenas que reconocen otros elementos además de la lengua para identificarse, como en el caso de los otomíes el parentesco y la sangre. Como señala Prieto (2014), las comunidades originarias han adoptado una identidad sustentada en la adscripción otomí de sus antepasados, en el recuerdo de los mayores y en la existencia de distintas creencias y prácticas visiblemente vinculadas a lo indígena. La lengua tiene importancia considerable, pero no es un factor determinante en la configuración o reconfiguración de las identidades étnicas, nacionales o culturales.

Vázquez y Prieto (2014) abordan las distintas maneras de identificarse como indígena en la ciudad de Querétaro. Los autores analizan las bases culturales de la identidad: la lengua, la comunidad, la 
ritualidad, la memoria histórica y los territorios originarios. En su estudio muestran que el ser indígena no solamente está definido por el uso de la lengua, la vestimenta, la gastronomía, las fiestas del pueblo y todo aquello que se relaciona con la tradición y las costumbres folclorizadas. En la actualidad, el ser indígena tiene relación con las comunidades que reinventan y revalorizan sus saberes y prácticas, son grupos que se reconocen en sus territorios, pero que también migran sin perder el sentido de lo propio. Sin embargo, precisamente este último aspecto, la migración, ha provocado que los indígenas dejen de hablar su lengua originaria y no la enseñen a las nuevas generaciones en respuesta a la dinámica del contexto urbano, como es el caso de la población indígena de la colonia Nueva Realidad. Siguiendo a estos autores, vale la pena destacar que en México, uno de los indicadores que expresan en términos censales la presencia de la población indígena en los territorios es el uso de la lengua. Sin embargo, tampoco es un factor determinante de pertenencias e identidades.

La lengua indígena ha dejado de practicarse por parte de las nuevas generaciones de la colonia Nueva Realidad, aunque siguen manteniendo otros rasgos identitarios y vínculos con su comunidad de origen. Bartolomé señala que "el abandono de la cultura no supone necesariamente la renuncia de la identidad" (Bartolomé 1997: 73). La lengua es un componente de la cultura que en algunos casos determina la filiación al grupo, pero como se ha mencionado no es el único. Para los otomíes las relaciones de parentesco son básicas para determinar la pertenencia. Asimismo, el constante contacto con la comunidad de origen permite que se conserven parte de las prácticas culturales después de haber negociado ciertos significados y generado estrategias adaptativas para socializarse en el contexto urbano. De modo que "lo cotidiano expresa entonces la presencia de una identidad social, de un nosotros diferenciado de cualquier otra identidad posible" (Bartolomé 1997: 85).

Es importante reflexionar, si la lengua ha dejado de practicarse en sus espacios tradicionales ¿en dónde está construyendo sus nuevos espacios performativos?, ¿quiénes son los que mantienen y le dan pertinencia a estas prácticas?, ¿cuáles son los contenidos culturales que se siguen trasladando y cuáles son aquellos que se quedarán para la memoria y el olvido? ¿Existen esas posibilidades en la cultura o la lengua será un elemento innecesario para las identidades indígenas de un mundo contemporáneo?

\section{Apuntes finales: los espacios ñäñho urbanos donde habita la lengua}

A la par de una situación complicada para la práctica extensa y reconocida de la lengua, la falta de políticas públicas que la impulsen, y en medio de una sociedad mayoritaria que históricamente discrimina, sucede que los otomíes que residen en la ciudad aún, consideran importante compartir con los hijos las historias relacionadas con la vida en el lugar de origen para que, a partir de estos relatos, los niños valoren su riqueza cultural.

"Para que sepan cómo era el trabajo que hacían para que saliera para comer, para sacar la tortilla, el maíz. Es importante que los niños vean cómo se trabaja la tierra, que vean cómo se hace el maíz, el elote, la mazorca para hacer las tortillas" (Flora, 32 años).

En Rico (2014) se relata la experiencia de talleres participativos que se llevaron a cabo con padres y abuelos otomíes como parte de una iniciativa de revitalización de la lengua originaria. En dichas sesiones, miembros de la primera y segunda generación eligieron los aspectos culturales por los que los otomíes urbanos sienten nostalgia, aquellas experiencias vividas en Santiago Mexquititlán que quisieran compartir con los niños que han crecido en la ciudad. Los elementos culturales que les parecen más significativos para ser socializados con los niños otomíes en la ciudad se pueden dividir en, al menos, ocho temas: el trabajo en el campo (siembra, cosecha, riego, sacar el zacate de la milpa, el cuidado y alimentación de los animales, ir a por la leña y partirla con hacha), la elaboración de artesanías (muñecas de tela, bordados, servilletas, lavar lana de borrego para hacer cobijas), la vestimenta (por qué las mujeres visten la ropa tradicional y qué significan los colores que usan, hablar sobre la vestimenta de manta de los hombres), la alimentación (hacer tortillas a mano, ir al molino, buscar hongos en el campo en tiempo de lluvias), las fiestas del pueblo (platicar sobre la historia y las tradiciones otomíes), los juegos y actividades lúdicas (subir a los árboles, hacer columpios con mecate en los árboles, jugar en la milpa, en el campo, al escondite, con las muñecas, con la pelota, con las flores, los trompos, las canicas, brincar la cuerda, salir a correr en el agua y en el lodo después de la lluvia, etc.), la vida en el pueblo (hablar sobre la tranquilidad en Santiago, levantarse temprano para ayudar a los padres en el trabajo, ir 
al pozo por agua, lavar la ropa en una piedra en las corrientes de agua, bañarse en el arroyo, juntar raíces de zacate para calentar agua, hacer tortillas y hacer fogatas), y la migración a las urbes (explicar por qué están en la ciudad).

Los elementos culturales mencionados hacen referencias a las vivencias en Santiago; los niños que han nacido y crecido en la ciudad no han podido experimentarlas y es por ello que a los abuelos y padres de familia les gustaría compartir historias alrededor de dichas expresiones, sensaciones, formas de socialización y maneras de transmisión de sistemas lingüísticos. Los adultos consideran importante la transmisión generacional de esos imaginarios, puesto que sin ellos los jóvenes y niños no aspiran al regreso y al reconocimiento de su lugar originario.

A partir de los aspectos de la cultura ñäñho antes mencionados, los padres y abuelos hicieron énfasis en la importancia de explicar a los niños qué es ser indígena y por qué se deben sentir orgullosos de serlo.

"Los niños deben entender que son indígenas, que sus padres hablan una lengua hermosa y que tienen tradiciones diferentes. Que tienen que hablar la lengua y que no pueden olvidar su origen porque lo traen en la sangre" (Teresa Clemente).

Un aspecto importante de señalar es que en muchas ocasiones, cuando los otomíes hablan de la lengua muestran una articulación intrínseca con la sangre, el parentesco y la filiación al grupo familiar. Para ellos, la lengua es una entidad donde circulan sus relaciones sociales más importantes; con la transformación de ella ven la modificación de vínculos sociales, los parentescos rituales, los compadrazgos, las familias extensas a partir de la organización social desde los linajes materno y paterno, se ven modificados al ya no tener conceptos culturales propios para designarlos y usarlos. Por eso, observamos que hay una estrechez de espacios sociales privados donde la lengua ha ido perdiendo su campo de acción. Sin embargo, este adelgazamiento de contextos ha provocado de manera simultánea un ensanchamiento de otros nichos culturales, por ejemplo, en los espacios oníricos.

Hoy en día, los etnógrafos que hacen trabajo de campo con indígenas urbanos reportan, de manera frecuente, las distintas alarmas culturales que utilizan estos grupos cuando se alejan de los elementos que conforman su identidad. Estas alarmas son sistemas normativos de corte moral, donde se expresan las acciones para obtener/recuperar la entrada o la permanencia al interior de un grupo determinado, faltar a la costumbre, a la devoción de una imagen, al cargo religioso; son situaciones donde las alarmas culturales se encienden y prescriben, por lo tanto, una acción para resarcir o equilibrar la afectación o el fallo. A veces estas alarmas se presentan en la parte diurna de la vida cotidiana, otras entre los sueños.

Entre los distintos casos analizados varios interlocutores nos hablan sobre sus sueños relacionados con su vocación lingüística. Algunos de ellos comentan que en medio de su sueño están escuchando voces en idiomas de tiempos actuales y pasados, a veces sueñan una lengua que no son conscientes cual es, otras sus sueños son en español, pero en contextos y situaciones ligadas a su comunidad de origen. También existen casos en los cuales las ensoñaciones son la lengua materna, donde ellos escuchan, comprenden y se comunican, donde saben que hay un mensaje y que tienen que descifrar su contenido para poder actuar en consecuencia a ello.

Una de las interlocutoras explica que a veces se sueña a sí misma hablando en español, pero vistiendo con la ropa tradicional de su pueblo. Esto muestra cómo los elementos culturales propios se distinguen fácilmente y se trasladan al territorio onírico de los otomíes. Ella se sueña representada con un elemento de visualización de la cultura que en la ciudad, como ella comenta, es difícil portar, puesto que es un emblema a la vez de orgullo, a la vez de discriminación. Sin embargo, en los sueños ella se mira bien.

Algunos abuelos comentan que sueñan en otomí. Sus sueños son en paisajes de la comunidad originaria, pero también en lugares urbanos en los cuales se comunican con amigos y familiares en la lengua materna, compartiendo códigos culturales donde la sociedad mayoritaria y sus elementos discriminatorios no inhiben la práctica lingüística. Es frecuente que en la generación de abuelos (mayores de 70 años) tengan este tipo de encuentros oníricos, donde sus parientes, amigos de la comunidad originaria, usualmente desde la lengua los incitan a regresar a atender la casa, la capilla, las fiestas y volver a sembrar.

En otras ocasiones, los ñäñho urbanos encuentran en los sueños los espacios para hacer los encuentros 
con familiares que están muy "lejanos". Una interlocutora nos explica que sueña que habla en la lengua originaria con sus hermanos que se encuentran demasiado lejos; esta adjetivación de distancia sucede porque sus hermanos ya fallecieron, pero ello no impide que se comunique en su lengua y se dé cuenta que aún después de muertos la gente sigue hablando ñäñho.

Y si los sueños parecen ser espacios virtuales, caóticos, complejos e inesperados (en gran parte parecido internet), por regla general son usualmente entendidos como una aproximación individual hacia la sociedad y la cultura que sucede de manera íntima y silenciosa. Sin embargo, la excepción a la regla la constituye la historia de una vecina ñäñho que nos comenta que, a veces, ha despertado en medio de la noche escuchando a su esposo dormido hablar en hñäñho.

Lo que hemos apuntado quizá no difiere de las situaciones oníricas en las comunidades indígenas de donde son originarios los ñäñho urbanos. Sin embargo, lo que hace la diferencia, es que ante un contexto de pérdida y riesgo, las alarmas culturales funcionan para poner mayor atención en el reto de la vida indígena en la ciudad. Aún entre muchos adultos y abuelos se sigue considerando que el hñäñho es la lengua con la que los otomíes se comunican con sus divinidades, ya sea para agradecer favores realizados o para pedir gracia y ayuda sagrada. Hablar es una de las cualidades que tiene que tener un niño para ser considerado individuo dentro del grupo parental y por eso es importante que el niño pueda hablar bien, que no tartamudee, que hable fluido. Una de las interlocutoras menciona que existe una oración específica para cuando ello sucede, pero que uno tiene que esperar hasta un momento preciso, específicamente cuando hay luna llena. Explica que se debe meter una llave en la boca del niño que tartamudea, de esta manera la luna "toma la llave" y le abre la boca al infante, facilitándole la articulación fluida de palabras.

Una de las versiones del rezo que se hace mientras se mete la llave en la boca del niño es la siguiente:

“Tsibi Zänä, / ga xoki ar jähne, / pa ñä xí hño pa hindar nk'une” (“Luz de luna, que le abra la boca para que hable bien y no tartamudee") (María de Lourdes, 43 años).

Otra de las versiones que existe como tratamiento a este padecimiento la comenta Alberta, cuando recuerda que su abuelita le dijo que cuando un niño no habla, lo deben llevar con el santito, especialmente con San Pedro y se le debe poner una moneda en la boca. Alberta explica que también se puede poner una llave en la boca del niño y ya a los dos meses empieza a hablar bien. Se le dice al santo:

"Gi ote 'nar bäts'i. / Gi xoko ar jähne, / pa da ñä. Pa dar hindar nk'une” ("Escucha al niño. Abre su boca para que hable, para que no tartamudee") (Alberta, 50 años).

Aspectos como soñar y rezar en otomí hablan de una presencia de la lengua originaria en los espacios más íntimos en la vida de los ñäñho urbanos. Lo que muestra la pervivencia de la lengua frente a la dinámica que la ciudad les plantea, de modo que no hablar en su lengua originaria en todos los ámbitos no se traduce en el olvido de lo propio, sino que la lengua y los aspectos culturales son los que llenan de significado a sus vivencias, interacciones, interpretaciones y prácticas.

La comunidad que constituyen los indígenas urbanos tiene una relectura constante de los elementos culturales que les significan y les son indispensables. Los lugares, al igual que los significados, se transforman y modifican a la par que sus relaciones sociales contraen, expanden y diluyen las fronteras de lo público y lo privado, mostrando que la lengua, así como sus códigos significantes, encuentran nuevos nichos donde florecen, se propagan y sonríen.

\section{Notas}

1. Los datos presentados en este texto provienen de la realización del trabajo de campo realizado durante 2013 y 2014 entre los indígenas urbanos de la Colonia Nueva Realidad. La manera en la cual fueron registradas las voces de los interlocutores fue mediante grupos de discusión y entrevistas a profundidad. Dicha actividad fue realizada por Karola Rico como parte del proceso de construcción de su tesis de Maestría en Estudios Amerindios y Educacion Bilingüe. 
2. Utilizamos la escritura propuesta por Hekking (2010), desarrollada en colaboración con hablantes nativos de Santiago Mexquititlán. Es una ortografía consistente, fonemática y estandarizada, discutida y aprobada por el Consejo de los Pueblos Indígenas de Querétaro en agosto de 1999.

3. En la siguiente página explicamos a detalle el origen y el significado del nombre de esta colonia con presencia indígena.

4. Diagnóstico, tipología de la violencia de género y perfil del agresor. El caso de las Mujeres Otomíes en la colonia Nueva Realidad (IQM 2008).

5. Para Nieto, un asentamiento congregado es el que se ubica en un espacio específico, delimitado por una región o una colonia en donde se ha establecido un número notable de población indígena (Nieto 2010: 92)

6. El Instituto Nacional de Estadística, Geografía e Informática, es la institución del Estado que proporciona los datos oficiales referentes a las características de la población en México.

\section{Bibliografía}

Bartolomé, Miguel Alberto

1997 Gente de costumbre y gente de razón. Las identidades étnicas en México. México D. F., INI-Siglo $\mathrm{XXI}$.

Bonfil, Guillermo

2003 México profundo. Una civilización negada. México D. F., Grijalbo.

Cohen, Anthony

1989 The Symbolic Construction of Community. Londres y Nueva York, Tavistock Publications.

Gupta, Akhil (y James Ferguson)

1997 "Beyond 'Culture': Space, Identity and the Politics of Difference", en Akhil Gupta y James Ferguson (eds.), Culture, Power, Place. Explorations in Critical Anthropology. Duke University Press, Durham and London: 33-51.

Biblioteca Virtual de Ciencias Sociales

Hekking, Ewald (y otros)

2010 Diccionario bilingüe otomí-español del Estado de Querétaro = He'mi mpomuhñä ar hñäñho ar hñämfo ndämaxei. México D. F., INALI.

Martín-Barbero, Jesús

1997 De los medios a las mediaciones. Comunicacion, cultura y hegemonia. Colombia, Convenio Andres Bello.

Martínez Casas, Regina

2002 "La invención de la adolescencia: las otomíes urbanas de Guadalajara", Boletín interno de los investigadores del área de Antropología: Diario de Campo, № 23, Diciembre, México D. F.: 22-35.

2007 Vivir invisibles. La resignificación cultural entre los otomíes urbanos de Guadalajara. Primera edición. México D. F., Centro de Investigaciones y Estudios Superiores en Antropología Social.

Martínez Casas, Regina (y Guillermo De la Peña)

2004 "Migrantes y comunidades morales: resignificación, etnicidad y redes sociales en Guadalajara", en Pablo Yanes, Virginia Molina y Oscar González (coords.), Ciudad, pueblos indígenas y etnicidad. México D. F, UCM/ Gobierno del Distrito Federal.

Murillo, Eunice

2011 La invención de lo imaginario. Intervención etnográfica como construcción de imágenes y significados. Tesis de licenciatura. Querétaro, Universidad Autónoma de Querétaro. 
Nieto, Jaime (y Cathia Huerta)

2010 Situación de la población indígena en la Ciudad de Santiago de Querétaro. Querétaro, Qro, CDI, UAQ, Universidad Marista de Querétaro.

Prieto, Diego (y Beatriz Utrilla)

2006 Ya hnini ya jä'itho Maxei. Los pueblos indios de Querétaro. Primera edición. México, D. F., CDI.

Rico, Karola

2014 Dí Pengi ga Pot'i, Volverme a Sembrar. Propuesta didáctica para la enseñanza de la lengua y la cultura ñäñho en la colonia Nueva Realidad. Tesis de Maestría. Querétaro, Universidad Autónoma de Querétaro.

Silva, José Luis.

2008 Diagnóstico, tipología de la violencia de género y perfil del agresor. El caso de las Mujeres Otomíes en la colonia Nueva Realidad. Querétaro, Instituto Queretano de la Mujer.

http://cedoc.inmujeres.gob.mx/lgamvlv/Queretaro/gro01.pdf.

Turner, Víctor

1999 La selva de los símbolos. México D. F., Siglo XXI.

Van Gennep, Arnold

1986 Los ritos de paso. Madrid, Taurus.

Vázquez, Alejandro (y Diego Prieto)

2013 Indios en la ciudad. Identidad, vida cotidiana e inclusión de la población indígena en la metrópoli queretana. Primera edición. México D. F., INAH.

Vázquez, Alejandro (y Diego Prieto)

2014 Los pueblos indígenas del Estado de Querétaro. Compendio monográfico. CDI, Delegación Estatal de Querétaro-UAQ.

Vázquez, Alejandro

2010 El pueblo está en todas partes. Las migraciones pames en el Estado de Querétaro. En Xi'ói Atlas etnográfico pames de la sierra gorda queretana. Querétaro, UAQ/ CDI/ Gob. Edo. de Querétaro/ Fundación DRT.

Yúdice, George

2002 El recurso de la cultura. Usos de la cultura en la era global. Barcelona, Gedisa. 